\title{
Effects of green tea leaf, lotus leaf, and kimchi powders on quality characteristics of chicken liver sausages
}

\author{
Juhui Choe, Gye-Woong Kim * and Hack-Youn Kim * \\ Department of Animal Resources Science, Kongju National University, Yesan 32439, Korea
}

\begin{abstract}
Liver sausage is flavorful and highly nutritious. However, liver has a relatively short shelf life due to acceleration of oxidation in the presence of endogenous enzymes and metals. Powders derived from natural sources, including plants or fruits, are applied to meat products for inhibiting oxidation without adverse effects on their quality. Hence, this study investigated the effects of natural powders derived from green tea leaf (GTL), lotus leaf (LL), and kimchi (KC) on the quality and change in lipid oxidation and freshness of chicken liver sausages during two weeks of storage. Chicken liver sausages were manufactured with chicken breast $(70 \%)$ and liver $(20 \%)$, pork back fat $(5 \%)$, iced water $(5 \%)$, various additives, and GTL, LL, and KC [0 (control) or 1\%]. They were processed in three batches. For determination of the quality characteristics of chicken liver sausages with various plant powders, $\mathrm{pH}$, color, and texture properties were assessed. In addition, lipid oxidation and freshness using thiobarbituric acid reactive substances (TBARS) and total volatile basic nitrogen (TVBN) were analyzed at day 0 and week 2 of refrigerated storage. Higher values were obtained for $\mathrm{pH}$ and cooking yield in sausage samples with $\mathrm{LL}$ and $\mathrm{KC}$ powders than in samples with the other treatments. For $\mathrm{a}^{*}$ values, the sausage samples with $\mathrm{KC}$ showed similar $(p>0.05)$ values, whilst others had significantly lower values than the control. The addition of the three powders to sausage samples induced an increase $(p<0.05)$ in hardness, gumminess, and chewiness. The addition of plant powders did not influence TBARS and TVBN of sausage samples at the initial stage. However, after two weeks of storage, significantly lower TBARS and TVBN values were observed, and the sausage with $\mathrm{KC}(p<0.05)$ showed the lowest values of both TBARS and TVBN. The results showed the potential ability of the three powders to improve the quality and inhibit lipid oxidation in liver sausages. Particularly, the addition of KC did not adversely affect the $\mathrm{a}^{*}$ values of sausage samples. The effects on sensory properties and inhibition mechanisms of GTL, LL, and KC in meat products should be further studied.
\end{abstract}

Keywords: Antioxidant activity, Green tea leaf, Kimchi, Liver sausages, Lotus leaf, Quality characteristics

\section{Introduction}

Liver sausage is a conventional and commonly consumed sausage type in Europe due to its highly flavorful characteristics [1,2]. Some studies have been conducted on its manufacturing process and the quality properties of meat products added with chicken

Received: Jan 10, 2019 Accepted: Jan 13,2019

"Corresponding author: Hack-Youn Kim, Department of Animal Resources Science, Kongju National University, Yesan 32439, Korea.

Tel: +82-41-330-1241, E-mail: kimhy@kongju.ac.kr

Gye-Woong Kim, Department of Animal Resources Science, Kongju National University, Yesan 32439, Korea.

Tel: +82-41-330-1245, E-mail: kimgoong@kongju.ac.kr

This is an Open Access article distributed under the terms of the Creative Commons Attribution Non-Commercial License (http://creativecommons.org/licenses/by$\mathrm{nc} / 4.0 /$ ) which permits unrestricted non-commercial use, distribution, and reproduction in any medium, provided the original work is properly cited.

Copyright (C) 2019 Korean Society of Animal Science and Technology. 
liver including coarse sausage [2] and spreadable sausage $[3,4]$ as a main ingredient. Chicken liver contains $24.6 \%$ protein, $6 \%$ fat, and high amounts of vitamin $\mathrm{A}$ and essential elements, including $\mathrm{Fe}, \mathrm{Zn}, \mathrm{Cu}, \mathrm{Mn}, \mathrm{Cd}, \mathrm{Pb}, \mathrm{Ni}$, and $\mathrm{Cr}$ [5]. However, liver has a relatively short shelf life and causes acceleration of oxidation due to the presence of endogenous enzymes and metals [6]. In addition, sausages made with chicken contain relatively high levels of unsaturated fatty acids. However, to the best of our knowledge, no studies have been reported on the inhibition of lipid oxidation in chicken liver sausages.

Plant sources, which contain polyphenols and flavonoids, have been applied to meat products as extracts or powders for inhibition or retardation of lipid oxidation during storage storage $[7,8]$. Green tea has been generally consumed as a beverage and is a traditional remedial agent used in East Asia. Furthermore, the powerful antioxidant activity of green tea related to polyphenols including catechin has been reported [9]. Lotus leaf (LL), widely used in both food and medicine, is known to have antioxidant, free radical scavenging, antibacterial, and anticardiovascular properties $[10,11]$. Kimchi (KC), a traditional fermented food in Korea, possess antioxidant properties and contains carotenoids, vitamins, flavonoids, and other polyphenols [12]. Addition of powders containing high amounts of dietary fiber as natural antioxidants could affect the quality properties of meat products, such as color and/or texture $[13,14]$. Hence, the aim of this study was to evaluate the effect of green tea leaf (GTL), LL, and KC powders on the quality characteristics of chicken liver sausages, including $\mathrm{pH}$, color, texture properties, change in lipid oxidation, and freshness during two weeks of storage.

\section{Materials and Methods}

\section{Preparation of powders of GTL, LL, and KC}

Green tea leaf, dried using a hot-air dryer, was purchased from Bosung in Chonnam, Korea. LL and Baechu KC (Chongga kimchi, Daesang FNF, Seoul, Korea) were purchased from a local market (Seoul, Korea). LL was thoroughly washed with water, chopped, and dried using a hot-air dryer (Enex-Co-600, Enex, Koyang, Korea) at $50^{\circ} \mathrm{C}$ for $15 \mathrm{~h}$. The $\mathrm{KC}$ was dried by a hotair dryer (Enex-Co-600, Enex, Koyang, Korea) at $60^{\circ} \mathrm{C}$ for $12 \mathrm{~h}$. The dried LL and KC were pulverized using a blender (KA-2610, Jworld Tech, Ansan, Korea) for 30 s, screened through a 35-mesh sieve, and stored at $-20^{\circ} \mathrm{C}$ until use.

\section{Preparation of materials}

Chicken breast and liver were purchased from a slaughterhouse (Seoul, Korea) and pork back fat was purchased from a local processor. All subcutaneous, intramuscular fat, and visible connective tissue were removed from the chicken breast. The trimmed chicken breast, liver, pork back fat were initially ground using an 8-mm plate.

\section{Preparation of chicken liver sausages}

The chicken liver sausages were produced in the following formulation: 70\% chicken breast, $20 \%$ chicken liver, $5 \%$ pork back fat, $5 \%$ iced water, $2 \%$ isolated soy protein (ISP), $1.5 \%$ nitrite pickled salt [salt:nitrite $=99.4: 0.6$; nitrite picked salt (NPS)], $0.25 \%$ sodium triphosphate, $0.5 \%$ sugar, $0.05 \%$ monosodium L-glutamate (MSG), $1.5 \%$ onion, $0.6 \%$ garlic, $0.2 \%$ ginger, and $0.03 \%$ black pepper. The ground chicken breast, pork back fat, and iced water were mixed in a silent cutter. Then, the additives (NPS, ISP, triphosphate, and spices) and $0 \%$ or $1 \%$ plant powders (GTL, $\mathrm{LL}$, and $\mathrm{KC}$ ) were added and homogenized. The ground chicken liver was added to the meat batter and mixed until the core temperature reached $9^{\circ} \mathrm{C} \pm 1^{\circ} \mathrm{C}$. The meat mixture was stuffed into collagen casings (\#240, NIPPI Inc., Tokyo, Japan; approximately 25 $\mathrm{mm}$ diameter) using a stuffer (IS-8, Sirman, Marsango, Italy), and each sample was cooked at $75^{\circ} \mathrm{C} \pm 1^{\circ} \mathrm{C}$ in a water bath for $30 \mathrm{~min}$ until the internal temperature reached $72{ }^{\circ} \mathrm{C}$. The cooked samples were immediately cooled in an ice bath, vacuum packed, and stored at $4{ }^{\circ} \mathrm{C}$ until $\mathrm{pH}$, color, texture properties, lipid oxidation, and total volatile basic nitrogen (TVBN) contents could be examined. The lipid oxidation and TVBN content were analyzed at week 0 and 2 of refrigerated storage $\left(4^{\circ} \mathrm{C}\right)$.

\section{Determination of $\mathrm{pH}$ and cooking yield}

The $\mathrm{pH}$ values for a mixture of sausage samples and distilled water (1:4) were determined using a pH-meter (Model 340, MettlerToledo GmbH Analytical, Schwerzenbach, Switzerland). The cooking yield in each treatment was determined by weighing meat batters before and after cooking and expressed in percentage.

\section{Instrumental color evaluation}

Color measurements were taken with a colorimeter (Chroma meter CR-210, Minolta, Japan; illuminant C, calibrated with a white standard plate $L^{*}=97.83, a^{*}=-0.43$, and $b^{*}=+1.98$ ), with an $8 \mathrm{~mm}$ diameter measuring area and a $50 \mathrm{~mm}$ diameter illumination area. Color values (CIE L*, $\mathrm{a}^{*}$, and $\mathrm{b}^{*}$ ) were measured on the surface of samples and results were taken in triplicate for each sample.

\section{Texture profile analysis (TPA)}

Samples were cut into sections with a height of $25 \mathrm{~mm}$ and $\varphi 16 \mathrm{~mm}$ diameter. The textural properties for each sample were measured using a cylinder probe ( $\varphi 20 \mathrm{~mm}$ diameter), set attached to a Texture Analyzer (TA-XT2i, Stable Micro System 
Ltd., Surrey, UK). The test conditions were as follows: stroke, 2 $\mathrm{kg}$; test speed, $2.0 \mathrm{~mm} / \mathrm{s}$; and distance, $8 \mathrm{~mm}$. The texture profile analysis (TPA) parameters, namely hardness $(\mathrm{kg} \cdot \mathrm{f})$, springiness, cohesiveness, gumminess, and chewiness $(\mathrm{kg} \cdot \mathrm{f})$ were computed.

\section{Determination of thiobarbituric acid reactive substances} (TBARS)

Lipid oxidation was assessed using the direct-distillation method as described by Tarladgis et al. [15], with minor modifications. Each sample at day 0 and week 2 of refrigerated storage was analyzed in triplicate. Briefly, $10 \mathrm{~g}$ of the sample was blended with $50 \mathrm{~mL}$ of distilled water prior to homogenization (AM-7, Nihonseiki Kaisha Ltd., Japan) at 10,900 $\times \mathrm{g}$ for $2 \mathrm{~min}$ and transferred to a distillation flask. The cup used for blending was washed with an additional $47.5 \mathrm{~mL}$ of distilled water, which was subsequently added to the same distillation flask containing $2.5 \mathrm{~mL}$ of $4 \mathrm{~N} \mathrm{HCl}$ and a few drops of an antifoaming agent, silicone o/w (KMK-73, Shin-Etsu Silicone Co., Ltd., Seoul, Korea). Then, the mixture was distilled and $50 \mathrm{~mL}$ of distillate was collected. Five $\mathrm{mL}$ of 0.02 M 2-thiobarbituric acid in 90\% acetic acid (TBA reagent) was added to a vial containing $5 \mathrm{~mL}$ of the distillate and mixed. The vials were capped and heated in a boiling water bath for $30 \mathrm{~min}$ to develop the chromogen and cooled to room temperature. The absorbance was measured at $538 \mathrm{~nm}$ (Libra S22, Biochrom Ltd., Cambridge, England) against a blank prepared with $5 \mathrm{~mL}$ distilled water and $5 \mathrm{~mL}$ TBA reagent. The $\mathrm{K}$ value was determined using 1,1,3,3-tetraethoxypropane (Sigma, USA) as the standard.

\section{Determination of total volatile basic nitrogen (TVBN)}

TVBN of the meat samples (at day 0 and week 2 of storage) was determined by the Conway microdiffusion method [8] and the results were expressed in $\mathrm{mg} \mathrm{N} / 100 \mathrm{~g}$ of sample.

\section{Statistical analysis}

Statistical analysis was performed by one-way analysis of variance (ANOVA), and significant differences $(p<0.05)$ were detected by
Duncan's multiple range test using SAS software (SAS, Release 8.01, SAS Institute Inc., USA). The values are expressed as means \pm standard deviation.

\section{Results and Discussion}

\section{$\mathrm{pH}$ and cooking yield}

The $\mathrm{pH}$ values of chicken liver sausages were affected by the type of powder (Table 1). The addition of GTL and LL powders to the sausages did not induce significant change in $\mathrm{pH}$ values compared to the control. However, sausage samples with $\mathrm{KC}$ powder had the lowest $(p<0.05) \mathrm{pH}$ values among the treatments. This result might be due to the presence of organic acids in KC. Similarly, Choe et al. [1] found that the $\mathrm{pH}$ of spreadable liver sausages increased with an increase in $\mathrm{KC}$ powder.

The cooking yield of meat and meat products is closely associated with fat and water retention [16]. In this study, the cooking yield of sausages added with GTL and LL powders did not differ from $(p>0.05)$ that of the control. On the other hand, the addition of $\mathrm{KC}$ in sausage samples resulted in a significant increase in cooking yield. A similar trend was found in spreadable liver sausages containing $\mathrm{KC}$ powder with addition levels of $1 \%$, $2 \%$, and $3 \%$ [1]. This result is supported by many authors who have documented an enhancement on water binding or holding ability by the addition of powders derived from plant and fruit containing dietary fiber in meat products $[17,18]$.

\section{Color}

The addition of non-meat ingredients in meat products could induce undesirable change in color, depending on its intrinsic color and addition level $[19,20]$. In this study, the addition of the powders (GTL, LL, and KC) to sausage samples significantly influenced the change in color (Table 1). The sausage samples containing GTL, LL, and KC powders showed lower $(p<0.05)$ values of $\mathrm{L}^{*}$ than the control. The three different powders led to a decrease in $L^{*}$ values. There was no difference $(p>0.05)$ in a*

Table 1. Effect of different plant powders on $\mathrm{pH}$, cooking yield, and color of chicken liver sausages

\begin{tabular}{llrrrr}
\hline \multirow{2}{*}{ Traits } & Control & \multicolumn{3}{c}{ Powder type } \\
\cline { 3 - 6 } & & & \multicolumn{1}{c}{ GTL } & LL & $6.32 \pm 0.02^{\mathrm{B}}$ \\
\hline $\mathrm{pH}$ & $6.39 \pm 0.02^{\mathrm{A}}$ & $6.38 \pm 0.03^{\mathrm{A}}$ & $6.37 \pm 0.02^{\mathrm{A}}$ & $97.18 \pm 0.53^{\mathrm{A}}$ \\
\hline Cooking yield & & $95.38 \pm 0.61^{\mathrm{B}}$ & $95.12 \pm 0.89^{\mathrm{B}}$ & $94.92 \pm 0.60^{\mathrm{B}}$ & $63.80 \pm 0.47^{\mathrm{B}}$ \\
\hline Color & $\mathrm{L}^{*}$ & $65.52 \pm 0.95^{\mathrm{A}}$ & $62.81 \pm 0.85^{\mathrm{B}}$ & $59.63 \pm 0.72^{\mathrm{C}}$ & $12.47 \pm 0.21^{\mathrm{A}}$ \\
& $\mathrm{a}^{*}$ & $12.38 \pm 0.41^{\mathrm{A}}$ & $5.54 \pm 0.22^{\mathrm{C}}$ & $5.89 \pm 0.20^{\mathrm{B}}$ & $21.84 \pm 0.41^{\mathrm{A}}$ \\
\hline
\end{tabular}

\footnotetext{
${ }^{A-C}$ Means $\pm S D$ with different superscript in the same row differ significantly $(p<0.05)$.

Control, chicken liver sausages without plant powders; GTL, chicken liver sausages with $1 \%$ green tea leaf powder; LL, chicken liver sausages with $1 \%$ lotus leaf powder; KC, chicken liver sausages with $1 \%$ kimchi powder.
} 
values between the control and sausage samples with $\mathrm{KC}$ powder. This result might be due to the intrinsic color of $\mathrm{KC}$ powder. The sausage samples with GTL and LL powders showed significantly lower a* values than those of the control and samples treated with KC powder. Some non-meat substance showing greenish color could induce higher $\mathrm{b}^{*}$ values in meat products. In this study, the sausage samples with GTL and KC powders showed a significant increase in $b^{*}$ values compared to the control and samples treated with LL powder. The sausage samples with LL had the lowest $(p<$ $0.05) b^{*}$ values among the treatments.

\section{TPA}

Generally, changes in soluble proteins and myofibrillar proteins by heat treatment contribute to texture properties of cooked meat products [21]. The texture properties in meat products are the most important factors indicating their functionality and quality properties. All samples treated with the plant powders showed significant higher values in hardness, gumminess, and chewiness compared to the control (Table 2). The sample treated with the LL powder had the highest $(p<0.05)$ values for hardness and gumminess among the treatments. A previous study found that incorporation of non-meat ingredients such as dietary fiber in sausage samples could influence hardness or springiness due to their greater water holding capacity [22]. In this study, no significant difference was observed in chewiness among the sausage samples with plant powders. Furthermore, the incorporation of the plant powders in sausage samples did not affect $(p<0.05)$ their springiness and cohesiveness. A similar trend was observed that control and sausages treated with Gaeddongssuk powder had similar values $(p>0.05)$ in cohesiveness [23].

\section{Lipid oxidation}

Lipid oxidation is commonly determined by measuring thiobarbituric acid reactive substances (TBARS), which are secondary lipid reaction products including aldehydes, carbonyls, and hydrocarbons [19]. In this study, TBARS values of sausage samples ranged from 0.17 to $0.28 \mathrm{mg} \mathrm{MDA} / \mathrm{kg}$ meat during two weeks of storage (Fig. 1). At initial storage (day 0), no significant difference in TBARS values was observed among the treatments. The TBARS values in sausage samples increased with an increase in storage time, showing $0.19-0.28 \mathrm{mg} \mathrm{MDA} / \mathrm{kg}$ meat. The result is probably due to the oxidation of unsaturated fatty acids of sausage samples. However, in this study, TBARS values during two weeks of storage were below the threshold value $(0.5 \mathrm{mg} \mathrm{MDA} /$ $\mathrm{kg}$ meat) [24] in meat products with a rancid taste. The sausage samples containing plant powders generally showed lower $(p<$ $0.05)$ values in TBARS compared to that of the control after two weeks of storage. This result indicates that lipid oxidation was effectively suppressed by GTL, LL, and KC powders, having high levels of phenolic compounds, compared to the control during storage. Many authors have reported on the antioxidant activities of GTL, LL, and KC [19, 25, 26]. The antioxidant activities of phenolic compounds are closely associated with the hydroxyl group attached to the aromatic ring, which is able to donate electrons with hydrogen atoms and neutralize free radicals. This mechanism blocks further degradation of more active oxidant forms, such as malondialdehyde [27].

\section{TVBN}

During storage, the action of microorganisms or enzymes can lead to decomposition of protein in meat and meat products and then ammonia, trimethylamine, and dimethylamine are produced, which can be measured as the TVBN content [8]. For this reason, TVBN is generally used as an indicator of freshness of meat and meat products. The TVBN values in sausage samples showed a similar trend to TBARS (Fig. 2). There was no significant difference in TVBN values among the treatments at day 0 of storage. However, at week 2 of storage, the control showed the highest $(p<0.05)$ values in TVBN of sausage samples relatively and the TVBN values depended on the powder type. Thus, at the final storage, the TVBN values of sausage samples were in the following order: control $(13.11 \mathrm{mg} \%)>$ GTL $(10.83 \mathrm{mg} \%)>$ LL $(9.24 \mathrm{mg} \%)>$

Table 2. Effect of different plant powders on texture properties of chicken liver sausages

\begin{tabular}{lllll}
\hline \multicolumn{1}{c}{ Traits } & Control & \multicolumn{3}{c}{ Powder type } \\
\cline { 3 - 5 } & & GTL & LL & KC \\
\hline Hardness $(\mathrm{kg})$ & $0.43 \pm 0.01^{\mathrm{C}}$ & $0.49 \pm 0.01^{\mathrm{B}}$ & $0.53 \pm 0.01^{\mathrm{A}}$ & $0.48 \pm 0.00^{\mathrm{B}}$ \\
Springiness & $0.96 \pm 0.03$ & $0.94 \pm 0.03$ & $0.93 \pm 0.05$ & $0.97 \pm 0.04$ \\
Cohesiveness & $0.50 \pm 0.03$ & $0.51 \pm 0.01$ & $0.51 \pm 0.02$ & $0.53 \pm 0.04$ \\
Gumminess (kg) & $0.22 \pm 0.01^{\mathrm{C}}$ & $0.25 \pm 0.01^{\mathrm{B}}$ & $0.27 \pm 0.01^{\mathrm{A}}$ & $0.25 \pm 0.02^{\mathrm{AB}}$ \\
Chewiness $(\mathrm{kg})$ & $0.21 \pm 0.02^{\mathrm{B}}$ & $0.24 \pm 0.01^{\mathrm{A}}$ & $0.25 \pm 0.02^{\mathrm{A}}$ & $0.24 \pm 0.02^{\mathrm{A}}$ \\
\hline
\end{tabular}

${ }^{A-C}$ Means $\pm S D$ with different superscript in the same row differ significantly $(p<0.05)$.

Control, chicken liver sausages without plant powders; GTL, chicken liver sausages with $1 \%$ green tea leaf powder; LL, chicken liver sausages with $1 \%$ lotus leaf powder; KC, chicken liver sausages with $1 \%$ kimchi powder. 


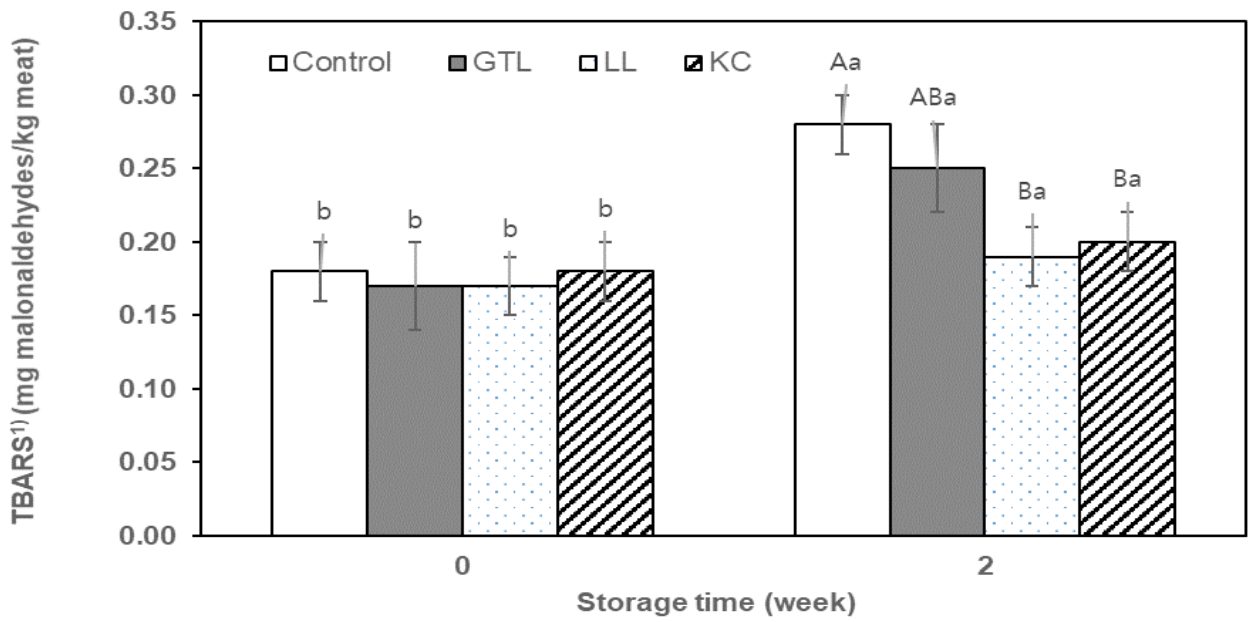

Fig. 1. Effect of different plant powder on lipid oxidation of chicken liver sausages. Each bar indicates standard deviation of means. ; ${ }^{A, B}$ Different letters within treatments of each storage day indicate significant differences $(p<0.05)$. ${ }^{a, b}$ Different letters within storage days of each treatment indicate significant differences $(p<0.05)$. TBARS, thiobarbituric acid reactive substances. Control, chicken liver sausages without plant powders; GTL, chicken liver sausages with $1 \%$ green tea leaf powder; LL, chicken liver sausages with $1 \%$ lotus leaf powder; $\mathrm{KC}$, chicken liver sausages with $1 \%$ kimchi powder.

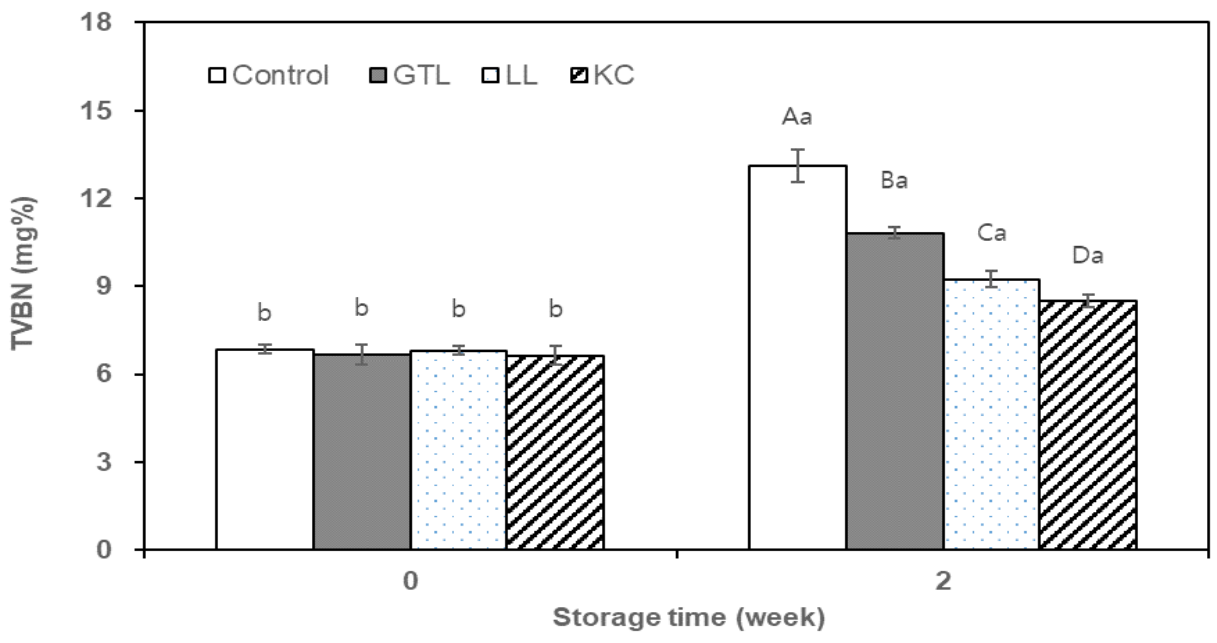

Fig. 2. Effect of different plant powder on total volatile basic nitrogen values (TVBN) of chicken liver sausages. Each bar indicates standard deviation of means. ${ }^{A-D}$ Different letters within treatments of each storage day indicate significant differences $(p<0.05)$. ${ }^{a, b}$ Different letters within storage days of each treatment indicate significant differences $(p<0.05)$. Control, chicken liver sausages without plant powders, GTL, chicken liver sausages with $1 \%$ green tea leaf powder; LL, chicken liver sausages with $1 \%$ lotus leaf powder; KC, chicken liver sausages with $1 \%$ kimchi powder.

$\mathrm{KC}(8.49 \mathrm{mg} \%)$. This result was probably due to the antimicrobial effect of GTL, LL, and KC, which was supported by previous studies $[11,28]$.

\section{Conclusion}

Based on the results of this study, GTL, LL, and KC powders effectively retard lipid oxidation and maintain freshness in chicken liver sausages. In particular, the addition of KC powder showed great improvement in the quality characteristics like cooking yield and similar a* values to control. Further studies based on the inhibition mechanisms of GTL, LL, and KC powders during storage against lipid and protein oxidation of meat products and their sensory properties should be performed.

\section{Competing interests}

No potential conflict of interest relevant to this article was reported.

\section{Funding sources}

This research was supported by Basic Science Research Program through the National Research Foundation of Korea (KRF) funded by the Ministry of Education (2017R1D1A1B03035488) 
and Mars Korea Co., Ltd.

\section{Acknowledgements}

Not applicable.

\section{Availability of data and material}

Upon reasonable request, the datasets of this study can be available from the corresponding author.

\section{Authors' contributions}

Conceptualization: Kim HY, Choe J.

Data curation: Kim HY.

Formal analysis: Choe J.

Software: Kim GW.

Investigation: Choe J, Kim GW.

Writing - original draft: Choe J.

Writing - review \& editing: Kim GW, Kim HY.

\section{Ethics approval and consent to participate}

This article does not require IRB/IACUC approval because there are no human and animal participants.

\section{ORCID}

Juhui Choe

Gye-WoongKim

https://orcid.org/0000-0003-4585-0327

Hack-Youn Kim https://orcid.org/0000-0001-7325-9898

https://orcid.org/0000-0001-5303-4595

\section{References}

1. Choe JH, Han DJ, Choi JH, Choi YS, Kim HY, Lee MA, et al. Effect of kimchi powder levels and pork skin on the quality characteristics of liver sausages. Korean J Food Sci Anim Resour. 2009;29:203-12.

2. Zhao XY, Gao GP, Yang Y. Development of new flavor sausage with chicken liver and garlic. Meat Industry. 2009. http://en.cnki.com. Accessed 5 Jan 2019.

3. Xiong G, Han M, Kang Z, Zhao Y, Xu X, Zhu Y. Evaluation of protein structural changes and water mobility in chicken liver paste batters prepared with plant oil substituting pork back-fat combined with pre-emulsification. Food Chem. 2016;196:388-95.

4. Steen L, Fraeye I, Mey ED, Goemaere O, Paelinck H, Foubert I. Effect of salt and liver/fat ratio on viscoelastic properties of liver paste and its intermediates. Food Bioprocess Technol. 2014:7;496-505.

5. Abu-Salem FM, Abou Arab EA. Chemical properties, Microbiological quality and sensory evaluation of chicken and duck liver paste (foie gras). Grasas Aceites. 2010;61:126-35.
6. Pyrcz J, Pietronczyck K, Kowalski R, Danyluk B. The effect of species origin of liver on quality of liver pate type sausage. Electron J Pol Agric Univ. 2006;9:21.

7. Aziz M, Karboune S. Natural antimicrobial/antioxidant agents in meat and poultry products as well as fruits and vegetables: a review. Crit Rev Food Sci Nutr. 2018;58:486-511.

8. Choe J, Kim YHB, Kim HY, Kim CJ. Evaluations of physicochemical and anti-oxiant properties of powdered leaves from lotus, shepherd's purse and goldenrod in restructured duck/pork patties.J Food Sci Technol. 2017;54:2494-502.

9. Donlao N, Ogawa Y. Impacts of processing conditions on digestive recovery of polyphenolic compounds and stability of the antioxidant activity of green tea infusion during in vitro gastrointestinal digestion. LWT-Food Sci Technol. 2018;89:648-56.

10. Yan K, Zhu H, Xu J, Pan H, Li N, Wang L, et al. Lotus leaf aqueous extract reduces visceral fat mass and ameliorates insulin resistance in HFD-induced obese rats by regulating PPAR gamma 2 expression. Front in Pharmacol. 2017;8:409.

11. Yisa J. Phytochemical analysis and antimicrobial activity of Scoparia dulcis and Nymphaea lotus. Aust J Basic Appl Sci. 2009;3:3975-9.

12. Sikaro E, Cieslik E, Leszczynska T, Filipiak-Florkiewicz A, Pisulewski PM. The antioxidant activity of selected cruciferous vegetables subjected to aquathermal processing. Food Chem. 2008;107:55-9.

13. Kim HS, Chin KB. Effects of drying temperature on antioxidant activities of tomato powder and storage stability of pork patties. Korean J Food Sci Anim Resour. 2016;36:51-60.

14. Yang HS, Choi SG, Jeon JT, Park GB, Joo ST. Textural and sensory properties of low fat pork sausages with added hydrated oatmeal and tofu as texture-modifying agents. Meat Sci. 2007;75:283-9.

15. Tarladgis BG, Watts BM, Younathan MT, Dugan L Jr. A distillation method for the quantitative determination of malonaldehyde in rancid foods. J Am Oil Chem Soc. 1960;37:44-8.

16. Aleson-Carbonell L, Fernandez-Lopez J, Perez-Alvarez JA, Kuri V. Characteristics of beef burger as influenced by various types of lemon albedo. Innov Food Sci Emerg Technol. 2005;6:247-55.

17. Henning SS, Tshalibe P, Hoffman LC. Physico-chemical properties of reduced-fat beef species sausage with pork back fat replaced by pineapple dietary fibres and water. LWT-Food Sci Technol. 2016;74:92-8.

18. Sharma SK, Bansal S, Mangal M, Dixit AK, Gupta RK, Mangal AK. Utilization of food processing by-products as dietary, functional, and novel fiber: a review. Crit Rev Food Sci 
Nutr. 2016;56:1647-61.

19. Choe JH, Choi JH, Choi YS, Han DJ, Kim HY, Lee MA, et al. Antioxidant properties of lotus leaf (Nelumbo nucifera) powder and barley leaf (Hordeum vulgare) powder in raw minced pork during chilled storage. Korean J Food Sci Anim Resour. 2011;31:32-9.

20. Serdaroglu M, Kavusan HS, Ipek G, Ozturk B. Evaluation of the quality of beef patties formulated with dried pumpkin pulp and seed. Korean J Food Sci Anim Resour. 2018;38:1-13.

21. Zayas JF, Naewbanij JO. The influence of microwave heating on the textural properties of meat and collagen solubilization.J Food Process Preserv. 1986;10:203-14.

22. Jeon SY, Baek JH, Jeong EJ, Cha YJ. Potential of onion peel extract as a functional ingredient for functional foods. J Life Sci. 2012;22:1207-13.

23. Ham HJ, Kang GH, Choi YS, Jeong TJ, Hwang KE, Kim CJ. Effect of Gaeddongssuk (Artemisia annua L.) powder on quality and shelf stability of emulsion sausages during refrigerated storage. Korean J Food Sci Anim Resour. 2016; 36:601-11.

24. Gray JI, Pearson AM. Rancidity and warmed-over flavor. In:
Pearson AM, Dutson TR, editors. Restructured meat and poultry products, advances in meat research. New York: Van Nostrand Reinhold; 1987.p. 221-69.

25. Lefe JY, Kunz B. The antioxidant properties of baechu-kimchi and freeze-dried kimchi-powder in fermented sausages. Meat Sci. 2005;69:741-7.

26. Ricci A, Parpinello GP, Palma AS, Teslíc N, Brilli C, Pizzi A, et al. Analytical profiling of food-grade extracts from grape (Vitis vinifera sp.) seeds and skins, green tea (Camellia sinensis) leaves and Limousin oak (Quercus robur) heartwood using MALDI-TOF-MS, ICP-MS and spectrophotometric methods. J Food Compos Anal. 2017;59:95-104.

27. Radha Krishnan K, Babuskin S, Azhagu Saravana Babu P, Sasikala M, Sabina K, Archana G, et al. Antimicrobial and antioxidant effects of spice extracts on the shelf life extension of raw chicken meat. Int J Food Microbiol. 2014;171:32-40.

28. Muriel-Galet V, Cran MJ, Bigger SW, Hernandez-Munoz P, Gavara R. Antioxidant and antimicrobial properties of ethylene vinyl alcohol copolymer films based on the release of oregano essential oil and green tea extract components. J Food Eng. 2015;149:9-16. 